\title{
Biomarkers and atrial fibrillation: A new paradigm for assessing the progression of left atrial endocardial remodelling
}

\author{
Philippe Chevalier ${ }^{1}$, Alina Scridon ${ }^{2}$ \\ ${ }^{1}$ Hospices Civils de Lyon, Hôpital Louis Pradel, Service de Rythmologie, Lyon, France \\ ${ }^{2}$ University of Medicine and Pharmacy of Targu Mures, Targu Mures, Romania \\ Email: philippe.chevalier@,chu-lyon.fr, alinascridon@yahoo.com
}

Received 29 December 2011; revised 13 February 2012; accepted 25 February 2012

\begin{abstract}
Atrial fibrillation is a heterogeneous disorder that is usually characterized by paroxysmal onset, particularly in patients without structural heart disease. Defining biological markers of atrial remodelling would help identify patients at high risk who would benefit most from prophylactic treatment and careful monitoring. Biomarkers of atrial fibrillation progression would be helpful for following patients that present with asymptomatic atrial fibrillation. Notably, the roles of such markers in the pathophysiology of atrial fibrillation must be determined. Some markers may indicate the presence, complications or progression of the disease, while others may be involved in key pathological processes and thus represent novel therapeutic targets. Although a number of markers have been reported as potential predictors of paroxysmal atrial fibrillation progression towards persistent arrhythmia, their usefulness and clinical value need further validation. This report reviews several newly identified markers of atrial fibrillation progression.
\end{abstract}

Keywords: Atrial Fibrillation; Biomarkers; Progression

\section{INTRODUCTION}

Atrial fibrillation is a heterogeneous disorder that varies in terms of clinical presentation, natural history, and response to therapy [1-3]. This cardiac arrhythmia is usually characterized by paroxysmal onset, particularly in patients without structural heart disease, but the natural history of the arrhythmia is to worsen [4]. Experiments in goats have shown that "atrial fibrillation begets atrial fibrillation" and that over the long term, atrial fibrillation progresses in frequency and duration to become persistent and finally permanent $[5,6]$.

However, it remains unclear whether paroxysmal, per- sistent and permanent atrial fibrillation represent three different stages of the same pathophysiological process or whether they represent three distinct disorders. Markers that predict the clinical progression of atrial fibrillation and its complications are yet to be defined.

\section{PREDICTORS OF ATRIAL FIBRILLATION PROGRESSION}

A number of clinical variables, such as valvular disease, alcohol consumption, age, left atrial dimension, and the occurrence of stroke or heart failure, have been proposed as predictors of atrial fibrillation progression [7]. In a retrospective study, Jahangir et al. identified older age at diagnosis and the presence of QRS abnormalities on ECG (prolonged QRS duration of 110 to $120 \mathrm{~ms}$, notching or slurring of the QRS complex, or low anterior forces with small $\mathrm{R}$ waves in the precordial leads) as predictors of progression towards permanent atrial fibrillation. However, age was the sole independent predictor of progression in multivariable analysis [8].

Several other parameters were also identified as predictors of the transition from paroxysmal to persistent atrial fibrillation, including duration of the arrhythmia [9], left ventricular dysfunction [10], enlarged left atria, prolonged filtered $\mathrm{P}$-wave duration, and a low root mean square voltage for the last $30 \mathrm{~ms}$ of the filtered $\mathrm{P}$ wave [11].

The CARAF study showed that a more rapid heart rate during atrial fibrillation at baseline is associated with a lower risk of developing permanent atrial fibrillation [12].

\section{BIOMARKERS OF ATRIAL FIBRILLATION PROGRESSION}

Biomarkers are defined as measurable components, such as cells, proteins and/or metabolic products that reflect, either directly or indirectly, one or more biological processes involved in a disease state [13]. Such markers help 
establish a diagnosis and may themselves be involved in subsequent pathobiological events.

\subsection{Inflammatory Burden and Atrial Fibrillation Progression}

Higher C-reactive protein levels have been observed in patients with persistent atrial fibrillation than in patients with paroxysmal atrial fibrillation, suggesting that $\mathrm{C}$ reactive protein levels may be related to the burden of atrial fibrillation [14].

Higher levels of YKL-40, a new biomarker of inflammation, have recently been documented in individuals with permanent atrial fibrillation compared to patients with persistent atrial fibrillation, further supporting the concept of an association between the chronicity of atrial fibrillation and the inflammatory burden [13].

Although there is abundant data suggesting a link between inflammation and atrial fibrillation, several studies failed to show elevated levels of C-reactive protein, interleukin-6, or interleukin-8 in atrial fibrillation patients [15-19].

A recent study was conducted in our department that included 81 subjects, 72 atrial fibrillation patients (39 with paroxysmal atrial fibrillation and 33 with persistent atrial fibrillation) and 9 control patients with Wolff-Parkinson-White syndrome. In the study, the levels of several inflammatory markers were determined in peripheral, coronary sinus, left atrial and pulmonary veins. There were no significant differences among the three groups regarding interleukin-8, soluble intercellular adhesion molecule- 1 or transforming growth factor $\beta 1$ levels at any of the sampling sites. Similarly, C-reactive protein levels, which were only measured in the peripheral blood, did not differ in the three groups. These results suggest that the high inflammatory marker levels reported in atrial fibrillation patients could be due to associated comorbidities rather than to atrial fibrillation per se [20].

\subsection{Markers at the Crossroads of Several Mechanisms}

In the same study that compared paroxysmal and persistent atrial fibrillation patients with controls without any history of atrial fibrillation [20], the peripheral levels of vascular endothelial growth factor (VEGF) were higher in both paroxysmal and persistent atrial fibrillation patients compared to controls (Figure 1). In the left atrium, VEGF levels were higher in the paroxysmal atrial fibrillation group compared to the control group; however, there was no significant difference between persistent atrial fibrillation patients and controls (Figure 1).

A number of pathological conditions induce VEGF secretion, including oxygen deficiency, inflammation, and pulsatile mechanical stretch [21]. Patients with atrial fib- rillation showed low levels of several inflammatory markers, regardless of the clinical form of the arrhythmia. This suggests that the inflammatory process is low grade, if present at all, in these patients. Therefore, it seems unlikely that inflammation alone could account for the high peripheral VEGF levels in atrial fibrillation patients. Despite the absence of evidence of accelerated angiogenesis in paroxysmal atrial fibrillation patients, we found high levels of VEGF in the left atrium in this population. Histopathological studies report a high incidence of atrial ischemia in up to $17 \%$ of autopsied patients with a history of atrial fibrillation and isolated atrial infarctions in more than $20 \%$ of them [22]. A transient increase in hypoxia inducible factor $\alpha$ (HIF $1 \alpha)$ gene expression, which is a known trigger for VEGF secretion, is reported in cardiac myocytes in the early onset of atrial fibrillation [23]. On the other hand, the inverse relationship is also a possibility, with ischemia favouring atrial fibrillation occurrence.

A fibrillating atrium leads to irregular blood flow and may induce pulsatile vascular stretch and impaired blood rheology with subsequent VEGF secretion in the peripheral blood [24-26]. Pulsatile mechanical stretch, recently postulated to be a potent trigger for VEGF secretion from cardiac myocytes [21,27], could lead to the high intracardiac VEGF levels observed in paroxysmal atrial fibrillation.

Nevertheless, it appears that left atrial secretion of VEGF is a transient event in the natural history of atrial fibrillation. Persistent atrial fibrillation is associated with more important fibrotic changes than the paroxysmal form (Figure 2) [28,29].

VEGF itself may be involved in these fibrotic changes, probably through the induction of angiogenesis [30-32]. The spreading of cardiac fibrosis may cause progressive

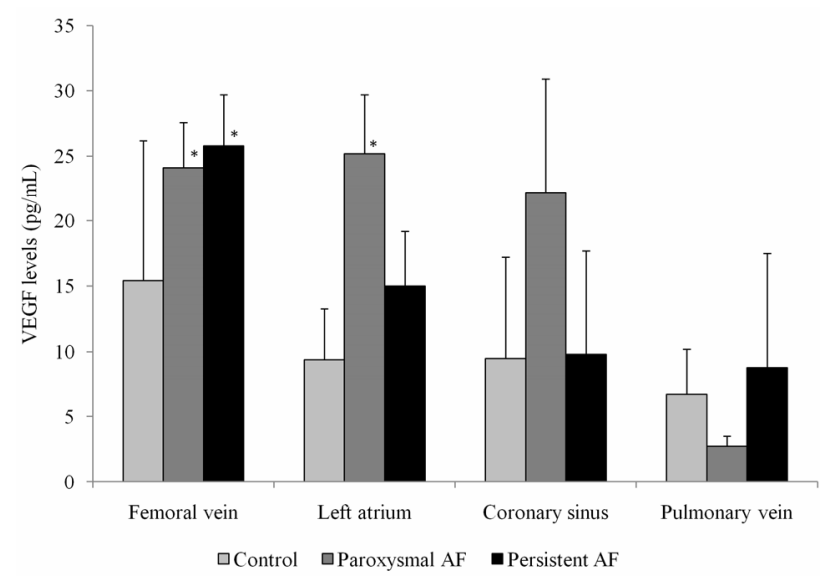

Figure 1. Mean levels of vascular endothelial growth factor (VEGF) in the femoral vein, left atrium, coronary sinus, and pulmonary vein in paroxysmal atrial fibrillation patients, persistent atrial fibrillation patients and in control patients with Wolff-Parkinson-White syndrome [20]. ${ }^{*} p<0.05$ vs. control. 


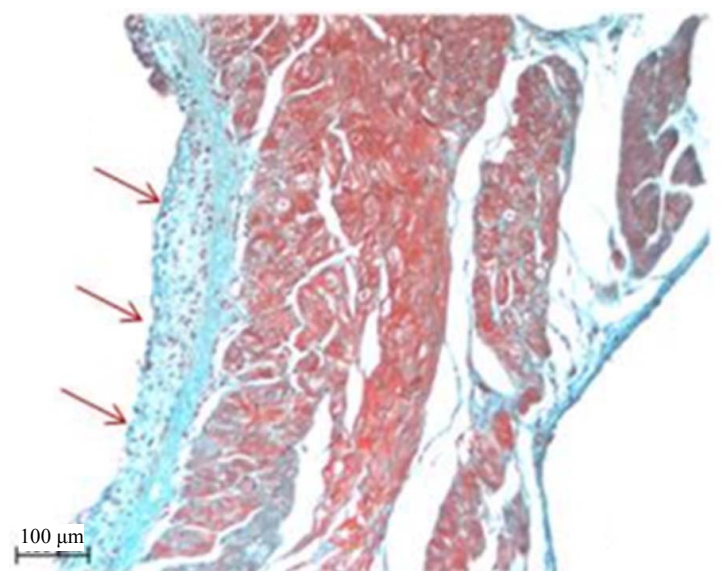

(a)

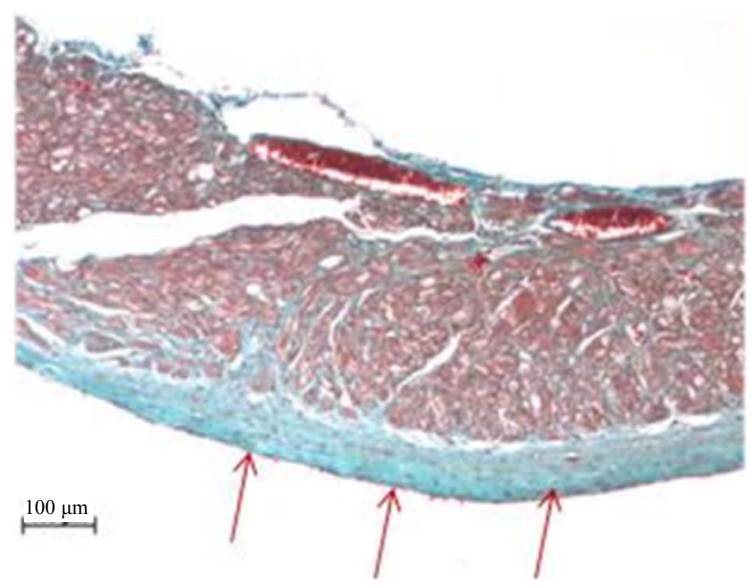

(b)

Figure 2. Left atrial samples (10×, Masson's trichrome staining) from aging spontaneously hypertensive rats presenting with atrial fibrillation. The samples show two stages of left atrial fibrosis, (a) Progressive, stratified endocardial fibrosis, and (b) Stable, evolved endocardial fibrosis. Red arrows indicate the endocardial layer.

cardiac stiffening, thereby reducing the degree of pulsatile stretch and subsequently diminishing intracardiac VEGF levels, as observed in patients with persistent atrial fibrillation. Thus, newly identified biomarkers, such as VEGF, may serve as predictors of atrial fibrillation progression.

\section{CONCLUSIONS}

Atrial fibrillation and related complications result from complex interactions of systemic conditions such as atherosclerosis, obesity, hypertension, and inflammation [15,33-38]. The progression of the arrhythmia towards more refractory forms seems to be related both to underlying conditions and to the extent of atrial remodelling [39]. Identifying biomarkers of atrial fibrillation progresssion would most benefit patients who present with asymptomatic atrial fibrillation. Preliminary results are encouraging, but prospective studies are needed to validate these indexes of worsening atrial disease.

\section{REFERENCES}

[1] Wyse, D.G. and Gersh, B.J. (2004) Atrial fibrillation: A perspective: Thinking inside and outside the box. Circulation, 109, 3089-3095.

http://circ.ahajournals.org/content/109/25/3089.full.pdf + html doi:10.1161/01.CIR.0000132611.01101.DC

[2] Feinberg, W.M., Blackshear, J.L., Laupacis, A., Kronmal, R. and Hart, R.G. (1995) Prevalence, age distribution, and gender of patients with atrial fibrillation: Analysis and implications. Archives of Internal Medicine, 155, 469-473. http://www.ncbi.nlm.nih.gov/pubmed/7864703 doi:10.1001/archinte.1995.00430050045005

[3] Go, A.S., Hylek, E.M., Phillips, K.A., Chang, Y., Henault, L.E., Selby, J.V. and Singer, D.E. (2001) Prevalence of diagnosed atrial fibrillation in adults: National implications for rhythm management and stroke prevention: The Anticoagulation and Risk Factors in Atrial Fibrillation (ATRIA) Study. Journal of the American Medical Association, 285, 2370-2375.

http://jama.ama-assn.org/content/285/18/2370.full.pdf+html doi:10.1001/jama.285.18.2370

[4] Chugh, S.S., Blackshear, J.L., Shen, W.K., Hammill, S.C. and Gersh, B.J. (2001) Epidemiology and natural history of atrial fibrillation: Clinical implications. Journal of the American College of Cardiology, 37, 371-378. http://content.onlinejacc.org/cgi/reprint/37/2/371.pdf doi:10.1016/S0735-1097(00)01107-4

[5] Wijffels, M.C., Kirchhof, C.J., Dorland, R. and Allessie, M.A. (1995) Atrial fibrillation begets atrial fibrillation: A study in awake chronically instrumented goats. Circulation, 92, 1954-1968.

http://circ.ahajournals.org/content/92/7/1954.full

[6] Allessie, M., Ausma, J. and Schotten, U. (2002) Electrical, contractile and structural remodeling during atrial fibrillation. Cardiovascular Research, 54, 230-246.

http://cardiovascres.oxfordjournals.org/content/54/2/230.full doi:10.1016/S0008-6363(02)00258-4

[7] de Vos, C.B., Pisters, R., Nieuwlaat, R., Prins, M.H., Tieleman, R.G., Coelen, R.J.S., van den Heijkant, A.C., Allessie, M.A. and Crijns, H.J.G.M. (2010) Progression from paroxysmal to persistent atrial fibrillation: Clinical correlates and prognosis. Journal of the American College of Cardiology, 55, 725-731.

http://content.onlinejacc.org/cgi/content/full/55/8/725 doi:10.1016/j.jacc.2009.11.040

[8] Jahangir, A., Lee, V., Friedman, P.A., Trusty, J.M., Hodge, D.O., Kopecky, S.L., Packer, D.L., Hammill, S.C., Shen, W.K. and Gersh, B.J. (2007) Long-term progression and outcomes with aging in patients with lone atrial fibrillation: A 30-year follow-up study. Circulation, 115, 3050-3056.

http://circ.ahajournals.org/content/115/24/3050.full doi:10.1161/CIRCULATIONAHA.106.644484

[9] Komatsu, T., Nakamura, S., Saitou, E., Kobayashi, T., Kumagai, K. and Okumura, K. (2000) Long-term efficacy 
of antiarrhythmic drugs in the prevention of paroxysmal atrial fibrillation; significance of suffering period. Japanese Journal of Electrocardiology, 1, 27-32.

[10] Kannel, W.B., Abbott, R.D., Savage, D.D. and McNamara, P.M. (1982) Epidemiologic features of chronic atrial fibrillation: The framingham study. New England Journal of Medicine, 306, 1018-1022.

http://www.ncbi.nlm.nih.gov/pubmed/7062992 doi:10.1056/NEJM198204293061703

[11] Abe, Y., Fukunami, M., Yamada, T., Ohmori, M., Shimonagata, T., Kumagai, K., Kim, J., Sanada, S., Hori, M. and Hoki, N. (1997) Prediction of transition to chronic atrial fibrillation in patients with paroxysmal atrial fibrillation by signal-averaged electrocardiography. Circulation, 96, 2612-2616. http://circ.ahajournals.org/content/96/8/2612.long

[12] Kerr, C.R., Humphries, K.H., Talajic, M., Klein, G.J., Connolly, S.J., Green, M., Boone, J., Sheldon, R., Dorian, P. and Newman, D. (2005) Progression to chronic atrial fibrillation after the initial diagnosis of paroxysmal atrial fibrillation: Results from the Canadian Registry of Atrial Fibrillation. American Heart Journal, 149, 489-496. http://www.medscape.com/viewarticle/502666 doi:10.1016/j.ahj.2004.09.053

[13] Henningsen, K.M., Therkelsen, S.K., Johansen, J.S., Bruunsgaard, H. and Svendsen, J.H. (2009) Plasma YKL-40, a new biomarker for atrial fibrillation? $E u$ ropace, 11, 1032-1036.

http://europace.oxfordjournals.org/content/11/8/1032.full doi:10.1093/europace/eup103

[14] Chung, M.K., Martin, D.O., Sprecher, D., Wazni, O., Kanderian, A., Carnes, C.A., Bauer, J.A., Tchou, P.J., Niebauer, M.J., Natale, A. and van Wagoner, D.R. (2001) C-reactive protein elevation in patients with atrial arrhythmias : Inflammatory mechanisms and persistence of atrial fibrillation. Circulation, 104, 2886-2891.

http://circ.ahajournals.org/content/104/24/2886.full doi:10.1161/hc4901.101760

[15] Conway, D.S., Buggins, P., Hughes, E. and Lip, G.Y. (2004) Relationship of interleukin-6 and C-reactive protein to the prothrombotic state in chronic atrial fibrillation. Journal of the American College of Cardiology, 43, 2075-2082.

http://content.onlinejacc.org/cgi/content/full/43/11/2075 doi:10.1016/j.jacc.2003.11.062

[16] Van Wagoner, D.R. (2008) Oxidative stress and inflammation in atrial fibrillation: Role in pathogenesis and potential as a therapeutic target. Journal of Cardiovascular Pharmacology, 52, 306-313.

http://www.ncbi.nlm.nih.gov/pubmed/18791466 doi:10.1097/FJC.0b013e31817f9398

[17] Liuba, I., Ahlmroth, H., Jonasson, L., Englund, A., Safstrom, K. and Walfridsson, H. (2008) Source of inflammatory markers in patients with atrial fibrillation. $E u$ ropace, 10, 848-853.

http://europace.oxfordjournals.org/content/10/7/848.full doi:10.1093/europace/eun111

[18] Ellinor, P.T., Low, A., Patton, K.K., Shea, M.A. and MacRae, C.A. (2006) C-reactive protein in lone atrial fibrillation. American Journal of Cardiology, 97, 1346-1350.
http://www.sciencedirect.com/science/article/pii/S000291 $\underline{4906001585}$

doi:10.1016/j.amjcard.2005.11.052

[19] Roldan, V., Marin, F., Blann, A.D., Garcia, A., Marco, P., Sogorb, F. and Lip, G.Y. (2003) Interleukin-6, endothelial activation and thrombogenesis in chronic atrial fibrillation. European Heart Journal, 24, 1373-1380. http://eurheartj.oxfordjournals.org/content/24/14/1373.full doi:10.1016/S0195-668X(03)00239-2

[20] Scridon, A., Morel, E., Nonin-Babary, E., Girerd, N., Fernandez, C., and Chevalier, P. (2012) Increased intracardiac vascular endothelial growth factor levels in patients with paroxysmal, but not persistent atrial fibrillation. Europace, in press.

http://europace.oxfordjournals.org/content/early/2012/02/ 02/europace.eur418.full

[21] Li, J., Hampton, T., Morgan, J.P. and Simons, M. (1997) Stretch-induced VEGF expression in the heart. Journal of Clinical Investigations, 100, 18-24. http://www.jci.org/articles/view/119510

[22] Wong, A.K., Marais, H.J., Jutzy, K., Capestany, G.A. and Marais, G.E. (1991) Isolated atrial infarction in a patient with single vessel disease of the sinus node artery. Chest, 100, 255-256.

http://chestjournal.chestpubs.org/content/100/1/255.full.p df + html doi:10.1378/chest.100.1.255

[23] Thijssen, V.L., van der Velden, H.M., van Ankeren, E.P., Ausma, J., Allessie, M.A., Borgers, M., van Eys, G.J. and Jongsma, H.J. (2002) Analysis of altered gene expression during sustained atrial fibrillation in the goat. Cardiovascular Research, 54, 427-437.

http://cardiovascres.oxfordjournals.org/content/54/2/427.full doi:10.1016/S0008-6363(02)00260-2

[24] Freeman, M.R., Scheck, F.X., Gagnon, M.L., Corless, C., Soker, S., Niknejad, K., Peoples, G.E. and Klagsbrun, M. (1995) Peripheral blood T-lymphocytes and lymphocytes infiltrating human cancers express vascular endothelial growth factor: A potential role for T cells in angiogenesis. Cancer Research, 55, 4140-4145. http://cancerres.aacrjournals.org/content/55/18/4140.full.pdf

[25] Gaudry, M., Bregerie, O., Andrieu, V., El Benna, J., Pocidalo, M.A. and Hakim, J. (1997) Intracellular pool of vascular endothelial growth factor in human neutrophils. Blood, 90, 4153-4161.

http://bloodjournal.hematologylibrary.org/content/90/10/ 4153.full.pdf

[26] Mohle, R., Green, D., Moore, M.A.S., Nachman, R.L. and Rafii, S. (1997) Constitutive production and thrombin-induced release of vascular endothelial growth factor by human megakaryocytes and platelets. Proceedings of the National Academy of Sciences USA, 94, 663-668. http://www.ncbi.nlm.nih.gov/pubmed/9012841 doi:10.1073/pnas.94.2.663

[27] Seko, Y., Seko, Y., Takahashi, N., Shibuya, M. and Yazaki, Y. (1999) Pulsatile stretch stimulates vascular endothelial growth factor (VEGF) secretion by cultured rat cardiac myocytes. Biochemical and Biophysical Research Communications, 254, 462-465.

http://www.sciencedirect.com/science/article/pii/S000629 
1 X98999697

doi:10.1006/bbrc. 1998.9969

[28] Kallergis, E.M., Manios, E.G., Kanoupakis, E.M., Mavrakis, H.E., Arfanakis, D.A., Maliaraki, N.E., Lathourakis, C.E., Chlouverakis, G.I. and Vardas, P.E. (2008) Extracellular matrix alterations in patients with paroxysmal and persistent atrial fibrillation: Biochemical assessment of collagen type-I turnover. Journal of the American College of Cardiology, 52, 211-215.

http://content.onlinejacc.org/cgi/content/full/52/3/211

[29] Gramley, F., Lorenzena, J., Koellensperger, E., Kettering, K., Weiss, C. and Munzel, T. (2010) Atrial fibrosis and atrial fibrillation: The role of the TGF- $\beta 1$ signaling pathway. International Journal of Cardiology, 143, 405-413. http://www.sciencedirect.com/science/article/pii/S016752 7309003969

doi:10.1016/j.ijcard.2009.03.110

[30] Chaudhary, N.I., Roth, G.J., Hilberg, F., Müller-Quernheim, J., Prasse, A., Zissel, G., Schnapp, A. and Park, J.E. (2007) Inhibition of PDGF, VEGF and FGF signalling attenuates fibrosis. European Respiratory Journal, 29, 976-985.

http://erj.ersjournals.com/content/29/5/976.full doi:10.1183/09031936.00152106

[31] Hamada, N., Kuwano, K., Yamada, M., Hagimoto, N., Hiasa, K., Egashira, K., Nakashima, N., Maeyama, T., Yoshimi, M. and Nakanishi, Y. (2005) Anti-vascular endothelial growth factor gene therapy attenuates lung injury and fibrosis in mice. Journal of Immunology, 175, 1224-1231.

http://www.jimmunol.org/content/175/2/1224.full

[32] Motomura, Y., Kanbayashi, H., Khan, W.I., Deng, Y., Blennerhassett, P.A., Margetts, P.J., Gauldie, J., Egashira, K. and Collins, S.M. (2005) The gene transfer of soluble VEGF type I receptor (Flt-1) attenuates peritoneal fibrosis formation in mice but not soluble TGF-beta type II receptor gene transfer. American Journal of Physiology: Gastrointestinal and Liver Physiology, 288, G143-G150. http://ajpgi.physiology.org/content/288/1/G143.full

[33] Jahangir, A., Munger, T.M., Packer, D.L. and Crijns, H.J.G.M. (2001) Atrial fibrillation. In: Podrid, P.J. and Kowey, P.R. Eds., Cardiac Arrhythmia: Mechanisms, Diagnosis, and Management, 2nd Edition, Lippincott Williams \& Wilkins, Philadelphia, 457-499.
[34] Tsang, T.S., Gersh, B.J., Appleton, C.P., Tajik, A.J., Barnes, M.E., Bailey, K.R., Oh, J.K., Leibson, C., Montgomery, S.C. and Seward, J.B. (2002) Left ventricular diastolic dysfunction as a predictor of the first diagnosed nonvalvular atrial fibrillation in 840 elderly men and women. Journal of the American College of Cardiology, 40, 1636-1644.

http://content.onlinejacc.org/cgi/content/full/40/9/1636 doi:10.1016/S0735-1097(02)02373-2

[35] Wang, T.J., Parise, H., Levy, D., D’Agostino, R.B. Sr., Wolf, P.A., Vasan, R.S. and Benjamin, E.J. (2004) Obesity and the risk of new-onset atrial fibrillation. Journal of the American Medical Association, 292, 2471-2477. http://jama.ama-assn.org/content/292/20/2471.full doi:10.1001/jama.292.20.2471

[36] Gami, A.S., Pressman, G., Caples, S.M., Kanagala, R., Gard, J.J., Davison, D.E., Malouf, J.F., Ammash, N.M., Friedman, P.A. and Somers, V.K. (2004) Association of atrial fibrillation and obstructive sleep apnea. Circulation, 110, 364-367.

http://circ.ahajournals.org/content/110/4/364.full doi:10.1161/01.CIR.0000136587.68725.8E

[37] Verdecchia, P., Reboldi, G., Gattobigio, R., Bentivoglio, M., Borgioni, C., Angeli, F., Carluccio, E., Sardone, M.G. and Porcellati, C. (2003) Atrial fibrillation in hypertension: Predictors and outcome. Hypertension, 41, 218-223. http://hyper.ahajournals.org/content/41/2/218.full

[38] Aviles, R.J., Martin, D.O., Apperson-Hansen, C., Houghtaling, P.L., Rautaharju, P., Kronmal, R.A., Tracy, R.P., Van Wagoner, D.R., Psaty, B.M., Lauer, M.S. and Chung, M.K. (2003) Inflammation as a risk factor for atrial fibrillation. Circulation, 108, 3006-3010. http://circ.ahajournals.org/content/108/24/3006.full doi:10.1161/01.CIR.0000103131.70301.4F

[39] Nieuwlaat, R., Prins, M.H., Le Heuzey, J.Y., Vardas, P.E., Aliot, E., Santini, M., Cobbe, S.M., Widdershoven, J.W.M.G., Baur, L.H., Levy, S. and Crijns, H.J.G.M. (2008) Prognosis, disease progression, and treatment of atrial fibrillation patients during 1 year: Follow-up of the Euro Heart Survey on Atrial Fibrillation. European Heart Journal, 29, 1181-1189.

http://eurheartj.oxfordjournals.org/content/29/9/1181.full doi:10.1093/eurheartj/ehn139 